\title{
Influence of lipofilling on the tissue structure of skin scars
}

\author{
N.N. Nor ${ }^{1,2}$, S.V. Slesarenko ${ }^{1,2}$, I.V. Baranov ${ }^{1}$, K.V. Tsyhankov ${ }^{3}$ \\ 1. Center of Thermal Trauma and Plastic Surgery, Dnipro \\ 2. SE "Dnipropetrovsk Medical Academy of Health Ministry of Ukraine" \\ 3. SE "Dnipropetrovsk City Multi-profile Clinical Hospital N4 of "DCC"
}

Purpose. Morphological grounding of applying the lipofilling operation for healing skin scars. Materials and Methods. 25 patients with skin scars after deep burns, who were undergoing treatment in the Center from 2014 till 2018, took part in the research. The histological examination was carried out using biopsy from areas in the scar tissue. The sampling materials took place before the operation and on the $14^{\text {th }}$ day after the lipofilling operation.

Results. The histological picture of the patients with atrophic and hypertrophic scars before the operation was characterized by similar pathological changes in the form of atrophic changes in epidermis with excessive pigmentation of the cells in the basal layer, skin appendages were sharply atrophic or absent. In the derma, the roughening of pulls of collagen fibers, hyalinosis of collagen fibers were observed; it was mainly manifested in the middle and lower thirds of the reticular layer, where band-shaped, ribbon-like areas of hyalinosis were formed (Fig.1).

In deep areas of derma, uneven intermittent edemas were revealed with the basophilia of connective tissue elements, a large number of variegated vessels (Fig.2). On the $14^{\text {th }}$ day after the operation the epidermis had a regular structure, the papillary and reticular layers of derma were represented by the unformed connective tissue with the significantly expressed capillary network and the insignificant center of perivascular lymphohistiocytic infiltration (Fig.3). The collagen fibers were well-contoured, formed the network of multidirectional pulls with clearly determined slit-like gaps between them. Occasionally small round cavities, which contained fat - protein detritus, were revealed. Singular small areas of maturing granular tissues with mono- and multivesicular structures were determined (Fig.4).

\section{References}

1. Alvaro Luiz Cansancao, Alexandra Conde-Green, Joshua A. David, B.S. Rafael A. Vidigal Subcutaneous-Only Gluteal Fat Grafting: A

Prospective Study of the Long-Term Results with Ultrasound Analysis //Plastic and Reconstructive Surgery . - 2019.- Vol. 143, N. 2 .- P.447451.

2.Coleman S.R., Mazzola R.F. Fat injection From Filling to

Regeneration //Quality Medical Publishing, Inc.St.Louis, Missouri.2009.-803p.

3.Di Rocco G., Iachininoto M.G., Tritarelli A. et al. Myogenic potential of adipose-tissuederived cells // J. Cell Sci. — 2006. — V. 119, N14. P. 2945-2952.

4.Hiko Hyakusoku, Dennis P. Orgill, Luc Teot, Julian J. Pribaz, Rei Ogawa. Color Atlas of Burn Reconstructive Surgery// Springer-Verlag Berlin Heidelberg. - 2010.- 491p.

5.Zuk P. A., Zhu M., Ashjian P. et al. Human adipose tissue is a source of multipotent stem cells // Mol. Biol. Cell. — 2002. — V. 13. — P. $4279-4295$.

Conclusions. The speed and completion of the regeneration processes in skin depends on the condition of the hypodermis adipose tissue.

Lipofilling could be considered as a method for the substitutive therapy at morpho-functional insufficiency of the hypoderm.

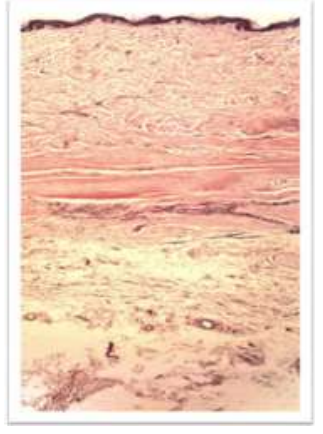

Fig. 1. Atrophic scar before surgery. Overall picture. $\times 40$.

Hematoxylin and eosin staining.

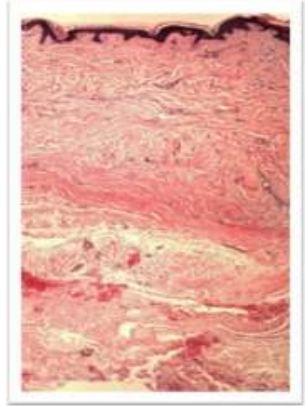

Fig.3. Atrophic scar after surgery lipofilling, 14 days. Overall picture. $\times 40$. Hematoxylin and eosin staining.

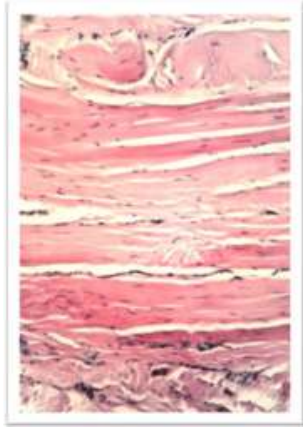

Fig. 2. Ribbon-like areas of hyalinosis $\times 100$.

Hematoxylin and eosin staining.

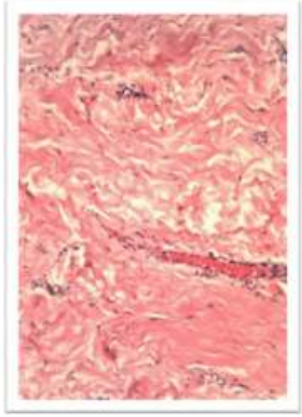

Fig.4. Hyalinosis zone loses solidity. Slit-like gaps between collagen fibers $\times 100$. Hematoxylin and eosin staining.

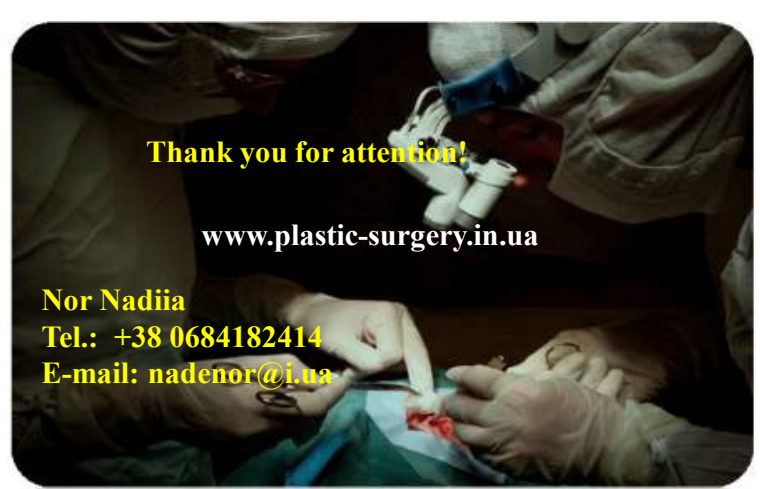

